John Caulfield as editor of this journal has made a commitment to devote each January's special issue of Optical Engineering to the topic of optical computing. I believe that this annual issue can become a significant factor in the advancement of the field. Optical computing is perhaps not yet a mature enough subject to have a journal dedicated exclusively to it. It is important, however, that consistent forums exist for the presentation of the advances and new directions that are being pursued in this area, particularly since this is an interdisciplinary field that is rapidly growing and changing. The special issue on optical computing will be edited by a different guest editor each year; John Neff (DARPA) will serve as the guest editor of next year's (January 1985) issue.

This first annual issue is, in my opinion, a fine start for what will, I hope, become a lasting tradition. The first two papers are excellent examples of the state of the art of optical signal processing systems today. The remaining four papers are indicative of current research efforts in new architectural design and numerical (systolic) optical computing. I thank the authors for their contributions and John Caulfield and the staff of Optical Engineering for their cooperation.

Guest Editorial

\title{
Optical Computing
}

Demetri Psaltis

California Institute of Technology

Department of Electrical Engineering

Pasadena, California 91125 